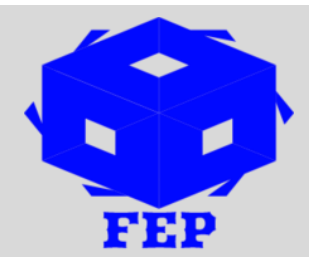

\title{
STUDY OF PHASES IN CRYSTALLINE SENTENCES
}

\author{
Oyewole Dipeolu ${ }^{1}$ \\ ${ }^{1}$ Department of Chemistry, Nigerian Defence Academy, Kaduna, Nigeria
}

*Corresponding Author: Oyewole Dipeolu

Article Received: 05-10-19
Accepted: 27-12-19
Published: $31-01-20$

Licensing Details: Author retains the right of this article. The article is distributed under the terms of the Creative Commons Attribution-Non Commercial 4.0 License (http://www.creativecommons.org/licences/by-nc/4.0/) which permits non-commercial use, reproduction and distribution of the work without further permission provided the original work is attributed as specified on the Journal open access page.

\section{ABSTRACT}

The objective of the study was to study the phases in the crystalline sentence of calcium molybdate with sodium metafanadat on the basis of phase equilibrium in binary sentence. For this study, different mixtures are prepared based on different molar ratios and investigation is made about these different mixture physical properties. Finally, the study also draw a phase balanced chart for the studied substances. For methodology adopted, nine samples were prepared. The results shows that to form a solid solution as dissolving sodium metafandate in calcium molybdate up to $40 \%$ of sodium metafanadate and form a solid solution in this sentence confirms that the necessary conditions to form a soid solution. It is concluded that for difference less than 15\%, unlimited solid solution is formed; whereas, for difference above $15 \%$, limited solid solution is formed. Our conclusion also shows that these two elements solubility is limited where one possesses the characteristic of high electronegativity, while, the other possess the characteristic of low electro negativity.

Keywords: Solid Crystalline, Compounds, Interaction, Chemistry

\section{INTRODUCTION}

Solid crystalline compounds are popular material in the previous century due to their desirable chemical properties and usage in wide range of fields such as use in construction material. The solid crystalline are also focus of the research since because of their industrial usage and electrical qualities such as piezo electric and electric capacitors (Jans, Dampier, Lakshminarayanan, Lorpens, and Tomkins, 1998). Their usage is also common in mining fields for purpose such as creating mixture for specific chemical, physical, and mechanical usage (Arndt, \& Gessler, 2008).

In modern researches, the focus is to further understand these compounds based on interactions of solid crystalline elements with each other or preparation of oxides or salts products. In this study, the objective is to study phases in the crystalline sentence of 
calcium molybdate with sodium metafanadat on the basis of the phase equilibrium in binary sentences. The relationship is presented as below.

$\mathrm{F}+\Phi=\mathrm{K}+\mathrm{n}$

Where $\mathrm{F}$ : number of degrees of freedom

$\Phi$ : number of crystalline phases

$\mathrm{K}$ : number of vehicles

$\mathrm{n}$ : external conditions of pressure and

temperature $(\mathrm{T}, \mathrm{P})$.

Different molar rations based on various temperature can be used to obtain crystalline compositions with regard to the salts taken, and permanent magnets are made ready or used as electrical savings or strong oxidizers. These compositions can be used in different technical fields such as paint or medicine (Baril, Labelle, Pekgal, \& Miner, 2003; Chase, 1983; Zhang, Sofo, \& Zikui, 2006). The idea of phase transformation provide basis to several natural sciences including chemistry, biology, and physics. It also provide ground to engineering sciences and is very common in nature too (Matiasovsky, Malinovsky, \& Danek, 1968; Grjotheim, Matiasovsky, Fellner, \& Silny, 1971; Gaebell, Meyer, 1983).

\section{Significance of the Study}

The study significance is that it provides useful information about obtaining crystalline compounds in the binary sentence of sodium Metafanadat with calcium molybdate. The study findings can be useful for the industrial sector and future researchers.

\section{Objectives of the Study}

The study is based on the following research objectives;

We aim to prepare various compounds in the binary sentence at various molar ratios consist of these steps.

Step 1: preparing different mixtures based on various molar ratios

Step 2: investigation and study of the physical properties of these mixtures

Step 3: draw a phased balanced chart for the studied substances.

\section{MATERIAL AND METHODS}

\section{Sampling}

We prepared nine samples based on various molar ratios and consisted of these steps.

First for each sample, the weight is set as per the 3 grams

We calculated molecular weights of each compounds in each sample according to molar ratios as follows;

Calcium Molybdate 200.01. molecular weight

Sodium Metafanadate 121.93. molecular weight

Sodium metafanadate 121.93. weight

For first sample, the proportion of calcium molybdate in which $10 \%$ of sodium metafandate is $90 \%$, the composition of the sample based on the following formula:

$1 \mathrm{CaMoO}_{4}, 9 \mathrm{NaVO}_{3}$

$200.01 \times 1+121.93 \times 9=1297.38 \mathrm{gr}$

$200.01 \div 1297.38=0.154 \mathrm{gr}$

$121.93 \times 9 \div 1297.38=0.845 \mathrm{gr}$ 
Weight of calcium molybdate in the first sample $0.154 \mathrm{gr}$.

The weight of sodium metafanadate in the second sample was $0.845 \mathrm{gr}$.

Thus the weight of calcium molybdate and sodium metafanadate in the nine samples is calculated according to the molar ratios taken as shown in Table (1).

Table 1: The weight of calcium molybdate and sodium metafanadate in the samples

\begin{tabular}{|c|c|c|c|c|}
\hline $\begin{array}{l}\text { Sample } \\
\text { Number }\end{array}$ & $\begin{array}{c}\text { Ratio } \\
\text { CaMoO4 in } \\
\text { the sample } \\
\%\end{array}$ & $\begin{array}{c}\text { Weigh } \\
\mathrm{CaMoO}_{4} \\
\text { in the sample } \\
\text { gr }\end{array}$ & $\begin{array}{c}\text { Ratio } \\
\text { NaVO3 in } \\
\text { the sample } \\
\%\end{array}$ & $\begin{array}{c}\text { Weigh } \mathrm{NaVO}_{3} \\
\text { in the sample } \\
\text { gr }\end{array}$ \\
\hline 1 & 10 & 0.254 & 90 & 0.945 \\
\hline 2 & 20 & 0.290 & 90 & 0.709 \\
\hline 3 & 30 & 0.422 & 70 & 0.597 \\
\hline 4 & 40 & 0.522 & 70 & 0.477 \\
\hline 5 & 50 & 0.720 & 50 & 0.479 \\
\hline 6 & 60 & 0.722 & 40 & 0.299 \\
\hline 7 & 70 & 0.792 & 40 & 0.207 \\
\hline 8 & 80 & 0.977 & 20 & 0.242 \\
\hline 9 & 90 & 0.947 & 20 & 0.074 \\
\hline
\end{tabular}

RESULTS AND DISCUSSION

1) Study of thermal changes in differential thermostats (DTA)

DTA technique was used for studying the nine samples

The first DTA spectrum consisted of $90 \%$ sodium metaandate and $10 \%$ calcium molybdate. Result shows that $80 \%$ sodium metafandate and $20 \%$ calcium molybdate based on DTA spectrum for the second sample is provided

$70 \%$ sodium metafandate and $30 \%$ calcium molybdate based on DTA spectrum for the third sample is provided.

$60 \%$ sodium metafanadate and $40 \%$ calcium molybdate based on DTA spectrum for the fourth sample is provided.

$50 \%$ sodium metafanadate and $50 \%$ calcium molybdate based on DTA spectrum for the fifth sample is provided.

$60 \%$ sodium metafanadate and $40 \%$ calcium molybdate based on DTA spectrum for the sixth sample is provided.

$70 \%$ sodium metafanadate and $30 \%$ calcium molybdate based on DTA spectrum for the seventh sample is provided.

$80 \%$ sodium metafanadate and $20 \%$ calcium molybdate based on DTA spectrum for the eight sample is provided.

$90 \%$ sodium metafanadate and $10 \%$ calcium molybdate based on DTA spectrum for the ninth sample is provided. 


\section{X-ray spectrometer}

Sodium metafanadate and calcium molybdate spectra were additionally studied using the XRD diffraction device along with the nine samples studied. The result shows that sodium metafanadate and calcium molybdate develop a solid solution which is based on dissolution of sodium metafanadate in calcium molybdate based on $40 \%$ of sodium metafanadate. Furthermore, for the remaining spectra which is exceeding $40 \%$ shows two phases in equilibrium called sodium metafanadate and calcium molybdate.

\section{CONCLUSIONS}

Based on the observation made from the X-ray spectra to form a solid solution as dissolving sodium metafanadate in calcium molybdate up to $40 \%$ of sodium metafanadate and form a solid solution in this sentence conforms that the necessary conditions to form a solid solution. Further, we conclude that for difference less than $15 \%$, unlimited solid solution is formed; whereas, for difference above $15 \%$, limited solid solution is formed. The difference is provided as below.

$31 \% . r=\mathrm{r}_{\mathrm{Ca}}-\mathrm{r}_{\mathrm{Na}}=1.97-1.66=0.31 * 100=31 \%$

Our conclusion also shows that these two elements solubility is limited where one possesses the characteristic of high electronegativity, while, the other possess the characteristic of low electrogenegativity. If compounds possess various crystalline models, then there will be limited decomposition. These two compounds may have different crystalline structure based on this study. $\mathrm{NaVO}_{3}$ sodium metafnadate has a monoclinc structure $\left(\mathrm{a}=5.034 \mathrm{~A}^{0}, \mathrm{~b}=\right.$ $\left.10.768 \mathrm{~A}^{0}, \mathrm{c}=5.108 \mathrm{~A}^{0}, \mathrm{~B}=90.86 \mathrm{~A}^{0}\right)$. Finally, our observation is that by observing the DTA scheme, there are phase transformations up to $40 \%$ of sodium metafanadate, and these phase transformations are caused by the presence of solid solution formed.

\section{References}

Arndt, K., Gessler A.Z. (2008). The Electrical Conductivity of Molten Oxidesl. 14, 662.

Baril, E., Labelle, P., Pekgal, P.O., \& Miner. J. (2003). Molten Salts Chemistry and Technology, 257, 1245.

Chase, N.W. (1983). Heat of transition of the elements, Bull. Alloy Phase Diagram.

Jans, C.J., Dampier F.W., Lakshminarayanan G.R., Lorpens P.K., Tomkins R.T. (1998).

"Molten Salts": Volume 1, Electrical Conductance, Density, and Viscosity Data", Nat.

Stand, Ref. DataSer, NBS (Oct.1998).

Lbov, V.S., \& Smirnov M.V. (1996). Electrocgemistry of Molten and Solid Electrolytes.

Matiasovsky, K., Malinovsky, M. (1966). Electrochim. Molten Salt Chemistry, 11, 1035.

Zhang, J., Sofo, J., Zikui, J. (2006). Systems Journal of alloys and compounds. 